\title{
Weiß, Michael Bastian, Der Autor als Individuum. Die Wende zum Subjekt in Ästhetik und Kunst des achtzehnten Jahrhunderts
}

\section{Élisabeth Décultot}

\section{OpenEdition}

Édition électronique

URL : http://journals.openedition.org/ifha/1708

DOI : $10.4000 /$ ifha. 1708

ISSN : 2198-8943

\section{Éditeur}

IFRA - Institut franco-allemand (sciences historiques et sociales)

Référence électronique

Élisabeth Décultot, «Weiß, Michael Bastian, Der Autor als Individuum. Die Wende zum Subjekt in Ästhetik und Kunst des achtzehnten Jahrhunderts », Revue de l'IFHA [En ligne], Date de recension, mis en ligne le 01 janvier 2008, consulté le 22 septembre 2020. URL : http://journals.openedition.org/ifha/1708 ; DOI : https://doi.org/10.4000/ifha.1708

Ce document a été généré automatiquement le 22 septembre 2020.

(C)IFHA 


\title{
Weiß, Michael Bastian, Der Autor als Individuum. Die Wende zum Subjekt in Ästhetik und Kunst des achtzehnten Jahrhunderts
}

\author{
Élisabeth Décultot
}

L'objet du présent ouvrage, ample par son volume comme par l'envergure de sa problématique, est d'analyser l'émergence de la notion d'auteur, compris comme individu créateur d'une œuvre artistique singulière, et le rôle dévolu à cette notion dans les textes philosophiques du XVIIIe s. Pour M.B.W., la notion d'auteur n'est certes pas une invention du siècle des Lumières : elle apparait à la Renaissance et se manifeste même dès la première moitié du XVe s., par exemple à travers l'inscription des noms de compositeurs ou d'exécutants sur certaines partitions musicales (p. 53 et suiv.). S'il évoque rapidement la multitude des facteurs qui ont pu contribuer à l'apparition de la figure auctoriale, M.B.W. choisit néanmoins de consacrer son étude à un aspect précis de ce phénomène : sa place dans les théories philosophiques du XVIIIe $s$. et plus particulièrement dans le mouvement qui conduisit, entre 1730 et 1790 environ, à l'émergence de "l'esthétique ", conçue comme discipline spécifiquement philosophique. Durant ces soixante-dix années, riches en publications majeures dans ce domaine, seules quelques figures retiennent l'attention de M.B.W., parmi lesquelles notamment celles de Baumgarten, de Charles Batteux pour ses Beaux-arts réduits à un même principe de 1747, d'Edward Young pour ses Conjectures upon Original Composition de 1759 et enfin de Karl Heinrich Heydenreich pour son System der Ästhetik de 1790. On peut peut-être regretter que le choix de ces figures, incontestablement importantes, de l'histoire esthétique ne fasse l'objet d'aucune justification développée et que les œuvres de contemporains non moins significatifs, tels Mendelssohn, Lessing ou Kant, ne soient évoquées qu'à la marge. Néanmoins, la cohérence de la sélection opérée apparaît peu à peu à la lecture de l'ouvrage et s'avère reposer sur un questionnement commun : quel rôle ces divers penseurs font-ils jouer à la notion d'auteur dans leurs réflexions sur l'art et sur sa perception? Si M.B.W. fait, 
selon toute attente, la démonstration de l'importance de cette notion dans la théorie d'Edward Young, penseur du principe d'" originalité ", il parvient aussi à montrer qu'elle occupe également, de façon moins attendue, une fonction centrale chez Batteux, dont le principe d'imitation n'exclut pas l'affirmation de l'individualité auctoriale. Quant à l'œuvre de K. H. Heydenreich, professeur de philosophie à Leipzig et émule de Kant, le présent ouvrage possède le grand mérite d'en éclairer des pans entiers, ignorés aujourd'hui, mais bien connus à la fin du XVIIIe s.

2 Élisabeth Décultot (Centre National de la Recherche Scientifique) 